\title{
Strategi Pemasaran Melalui Digital Marketing Pada Pariwisata Kota Lama Semarang
}

\author{
Leonardo Budi H dan Dheasey Amboningtyas \\ Prodi Studi Manajemen Pandanaran Semarang, Indonesia \\ Email corresponding author: \\ leonardobudihas@yahoo.com/dheasey@unpand.ac.id
}

\begin{abstract}
ABSTRAK
Digital Marketing menggambarkan pengguna utama teknologi digital untuk mendukung fungsi pemasaran suatu organisasi. Dalam upaya meningkatkan pemasaran dan menjangkau target pasar melalui digital marketing, pengurus pariwisata Kota Lama Semarang perlu menggunakan alat-alat penyebaran informasi dan promosi penjualan secara online, seperti menggunakan media sosial dan website, ini adalah alat penyebaran informasi secara digital yang dapat diakses oleh seluruh masyarakat dunia sehingga penyebaran informasi dan promosi penjualan dapat tersampaikan dengan baik. Tujuan penelitiaan ini untuk mempelajari digital marketing yang digunakan dan dikembangkan pada Pariwisata Kota Lama Semarang. Penerapan Digital Marketing menggunakan lima digital marketing yang menjadi media komunikasi pemasaran dan promosi untuk konsumen. Lima digital marketing online tersebut adalah media sosial diantaranya ada instagram, facebook, instant messanger atau whatsapp, e-mail serta website. Ini digunakan guna memberikan fasilitas kepada konsumen untuk berkomunikasi, menginformasikan produk yang ditawarkan, mengenalkan kepada konsumen, mengikuti perkembangan zaman di dunia bisnis dan memenuhi kebutuhan konsumen. Bauran Pemasaran Digital Terdapat 7 elemen bauran pemasaran digital yang digunakan untuk mendukung komunikasi pemasarannya kepada konsumen yaitu Produk (Product), Harga (Price), Tempat (Place), Promosi (Promotion), Orang (People), Proses (Process), Bentuk Fisik (Physical Evidence).
\end{abstract}

Kata Kunci Digital Marketing, Media Sosial, Pemasaran, dan Bauran Pemasaran

\begin{abstract}
Digital Marketing describes the main users of digital technology to support the marketing function of an organization. In an effort to improve marketing and reach the target market through digital marketing, Semarang Old Town tourism management needs to use online information dissemination and sales promotion tools, such as using social media and websites, these are digital information dissemination tools that can be accessed by the entire community. the world so that information dissemination and sales promotion can be conveyed properly. The purpose of this research is to study digital marketing that is used and developed in Semarang Old Town Tourism. The implementation of Digital Marketing uses five digital marketing media which are marketing and promotional communication media for consumers. The five online digital marketing are social media including Instagram, Facebook, instant messenger or whatsapp, e-mail and websites. This is used to provide facilities for consumers to communicate, inform the products offered, introduce them to consumers, keep up with the times in the business world and meet consumer needs. Digital Marketing Mix There are 7 elements of the digital marketing mix that are used to support marketing communications to consumers, namely Product, Price, Place, Promotion, People, Process, Physical Form (Physical Evidence).
\end{abstract}

Keywords: Digital Marketing, Social Media, Marketing and Marketing Mix 


\section{PENDAHULUAN}

Indonesia merupakan salah satu negara yang menjadi pilihan turis manca negara untuk berlibur. Sebab itu jasa pariwisata di Indonesia menempati urutan ketiga dalam hal penerimaan devisa negara setelah komoditi minyak dan gas bumi serta minyak kelapa sawit. Di setiap sudut pulau di Indonesia terdapat objek wisata yang unik dan asik untuk di kunjungi, fakta ini menjadi pengaruh bagi para wisatawan asing ataupun domestik untuk berkunjung dan berlibur. Selain tempat wisata yang unik dan asik, ada pula masyarakat Indonesia yang terbiasa dengan berekreasi atau yang umumnya disebut piknik. Dalam hal ini pemerintah berupaya memperbaiki segala fasilitas demi kenyamanan pengunjung dan pemerintah menghimbau agar pengunjung tetap menjaga kebersihan tempat wisata. Teknologi digital menjadi tren baru bagi setiap individu. Kesempatan aksessetiap saat, dapat diakses dimana saja, serta waktu akses yang cepat menjadi daya tarik besar teknologi digital. Teknologi digital dan elektronik sebagai data utama, merubah aktivitas manusia, mulai dari proses secara tradisional menjadi interaksi menjadi jejaring internet

Pada akhirnya, teknologi diartikan sebagai interpreter dan fasilitator (Sutabri, 2014), karena penggunaan teknologi digital, seperti media sosial dianggap sebagai penghubung manusia melalui bentuk interface, serta menjadi fasilitas penting dalam interaksi. Anggapan ini semakin berkembang dimasa pandemic covid-19. Batasan jarak dan ruang untuk interaksi tatap muka, menjadikan individu berinteraksi secara daring melalui media sosial, seperti whatsapp, instagram, twitter atau facebook.Kemunculan berbagai aplikasi media sosial menciptakan peluang usaha bagi masyarakat.Peluang terhadap media sosial tidak berhenti hanya pada usaha produk, tetapi juga jasa sepertipariwisata yang mulai menggunakan media sosial sebagai salah satu sarana untuk menarik perhatian masyarakat.

Dengan adanya tempat wisata masyarakat setempat dapat merasakan dampak positif dan negatif. Dampak positif yang dimaksud adalah perubahan sosial ekonomi pada masyarakat, dengan adanya penemuan tempat wisata di lingkungan tempat tinggal mereka, masyarakat sekitar dapat membangun dan mengembangkan serta membuka jasa pariwisata atau menjadi tour guide bagi wisatawan yang sedang berkunjung. Sedangkan dampak negatif yang dimaksud adalah adanya penggusuran rumah masyarakat sekitar untuk dijadikan lahan parkir atau perluasan wilayah tempat wisata. Maka dari itu pemerintah menunjuk beberapa perusahaan untuk mengatur dan mengelola tempat-tempat wisata yang bersifat rekreatif dan edukatif agar terciptanya kenyamanan bagi seluruh masyarakat. Metode pariwisata melalui media sosial dimaksudkan untuk memasarkan produk atau jasa dibidang pariwisata, dengan memberikan informasi tertentu kepada konsumen.

Digital Marketing menggambarkan pengguna utama teknologi digital untuk mendukung fungsi pemasaran suatu organisasi. Dalam organisasi itu memahami fungsi pemasaran, Teknik digital digabungkan dengan bentuk tradisional dari kegiatan pemasaran. Namun, dalam bisnis digital tradisi kegiatan nasional dipimpin oleh, dipandu dan terintegrasi dengan pemasaran digital. Sinonim untuk pemasaran digital termasuk pemasaran elektronik, pemasaran online marketing dan pemasaran internet. Pemasaran digital mencakup pengiriman konten online kepada pelanggan untuk menarik dan melibatkan mereka dalam aktivitas ikatan yang terkait dengan barang dan layanan bisnis ( Heinze, Fletcher, Rashid, \& Cruz, 2016 ). Istilah "Internet Marketing" banyak digunakan untuk merujuk pada perspektif eksternal tentang bagaimana internet dapat digunakan bersama dengan media tradisional untuk memperoleh dan memberikan layanan kepada pelanggan. Komunikasi pemasaran dapat dilakukan melalui media sosial dengan tujuan untukmenumbuhkan minat konsumen, karena minat baru muncul ketika konsumen merespon rangsangan berupa objek yang menarik bagi konsumen. Minat berunjung pada wahana wisatamisalnya, lahir karena adanya keinginan didalam diri konsumen 
terhadap suatu produk, yangsebelumnya telah diamati dan dipelajari oleh konsumen (Durianto, 2013).

Saat ini, pemasaran digital adalah istilah yang paling umum digunakan, yang mengacu pada setiap pengguna teknologi untuk mencapai tujuan pemasaran dan memiliki eksternal dan internal perspektif. Ini lebih konsisten dengan konsep bisnis digital, yang melibatkan pengelolaan komunikasi digital internal dan eksternal (Chaffey, Hemphill, Edmundson-Bird., 2019). Saat ini banyak masyarakat yang menggunakan media sosial untuk melengkapi aktivitas sehari-harinya untuk melakukan pembelian, mengakses informasi, maupun berkomunikasi. Dalam upaya meningkatkan pemasaran dan mengjangkau target pasar melalui digital marketing, perusahaan perlu menggunakan alat-alat penyebaran informasi dan promosi penjualan secara online, seperti menggunakan media sosial dan website, ini adalah alat penyebaran informasi secara digital yang dapat diakses oleh seluruh masyarakat dunia sehingga penyebaran informasi dan promosi penjualan dapat tersampaikan dengan baik. Berdasarkan kepada permasalahan diatas, maka tujuan penelitian ini adalah untuk mempelajari digital marketing yang digunakan pada pariwisata Kota Lama Semarang dan mempelajari perkembangan digital marketing pada pariwisata Kota Lama Semarang.

\section{METODE PENELITIAN}

Pendekatan yang digunakan dalam penelitian ini adalah pendekatan kuantitatif, dengan jenis penelitian deskriptif. Deskriptif digunakan untuk mendeskripsikan mengenai pengaruh dari variabel independen terhadap variabel dependen (Sugiyono, 2016). Variabel independen atau variabel bebas dalam penelitian ini adalah menggunakan e-marketing berupa media sosial Instagram, dengan dimensi Homepage, Komentar dan Like, Instagram Story, Caption, Lokasi, dan Hashtag(\#). Untuk teknik pengumpulan data dilakukan pengumpulan data primer melalui kuesioner, dan data pendukung berupa data sekunder melalui studi kepustakaan dan dokumentasi. Adapunpopulasi atau sampel dalam penelitian ini adalah pengguna instagram yang mengikuti akun Kotalama Semarang dengan 9.801followers, dengansampel sebanyak 100 responden.

\section{HASIL DAN PEMBAHASAN}

\section{Pemasaran}

Menurut Kotler \& Keller (2012) Pemasaran adalah proses sosial dimana individu dan kelompok memperoleh apa yang mereka butuhkan dan inginkan melalui menciptakan, menawarkan, dan bertukar secara bebas produk dan layanan bernilai dengan lainnya. Lalu Kotler \& Keller (2012) juga mengatakan Pemasaran adalah suatu organisasi dan serangkaian proses unutk menciptakan, dan memberikan nilai kepada pelanggan dan unutk mengelola hubungan pelanggan dengan cara yang menguntungkan organisasi dan para pemangku kepentingannya. Kemudian Kotler (2002) sendiri memberi definisi Pemasaran adalah suatu proses yang didalamnya individu dan kelompok mendapatkan apa yang mereka butuhkan dan inginkan dengan menciptakan, menawarkan dan secara bebas mempertukarkan produk yang bernilai dengan pihak lain. Sedangkan Kotler, Brown, Adam \& Armstrong (2004) juga mengatakan bahwa pemasaran adalah upaya mewujudkan nilai dan kepuasan pelanggan dengan mendapatkan laba. Pemasaran adalah proses aktivitas bisnis individu atau organisasi yang 10 menciptakan, menyediakan, menawarkan dan menyampaikan barang dan jasa ke konsumen dalam upaya memuaskan konsumen serta mendapatkan laba untuk perusahaan, jadi dalam kegiatan ini dua belah pihak dapat saling merasa puas. 


\section{Fungsi Pemasaran}

Dalam pemasaran memiliki beberapa fungsi, fungsi utama pemasaran menurut Tjiptono (2004) adalah menginformasikan, mempengaruhi, serta mengingatkan konsumen tentang perusahaan dan bauran pemasarannya.

\section{Strategi Pemasaran}

Strategi pemasaran adalah serangkaian tujuan dan sasaran, kebijakan dan aturan yang memberi arah kepada usaha-usaha pemasaran perusahaan dari waktu, pada masing-masing tingkatan dan acuan serta alokasinya, terutama sebagai tanggapan perusahaan dalam menghadapi lingkungan dan keadaan 12 persaingan yang selalu berubah (Assuri, 2013). Dalam berikut strategi pemasaran berarti upaya-upaya yang dilakukan oleh perusahaan atau penjual bertujuan untuk memasarkan suatu produk atau jasa yang ditawarkan agar tersampaikan dengan baik, kepada orang yang tepat, dalam lokasi yang dapat di jangkau oleh banyak orang, serta dapat terciptanya suatu selarasan dalam menghadapi lingkungan dan keadaan persaingan yang selalu berubah.

\section{Bauran Pemasaran ( Marketing Mix)}

Untuk menyampaikan informasi penjualan dari penjual hingga sampai ke tangan konsumen tidak mudah, perusahaan harus mengenali sasaran pasar, produk yang diperlukan, harga yang sesuai, promosi yang tepat dan tempat yang strategis. Bauran Pemasaran atau Marketing Mix adalah seperangkat alat pemasaran yang digunakan perusahaan untuk terus-menerus mencapai tujuan pemasarannya di pasar sasaran (Kotler, 2002)

\section{Komunikasi Massa}

Komunikasi massa adalah salah satu bentuk komunikasi yang menggunakan media massa, baik cetak maupun elektronik, dikelola oleh pribadi, lembaga ataupun organisasi, dengan tujuan khalayak yang tersebar luas dan heterogen (Tambunan, 2018). Komunikasi massa cenderung dipahami sebagai komunikasi yang bersifat satu arah, dimana komunikator adalah pemegang kendali atas arus informasi yang disampaikan. Dapat dikatakan bahwa media massa sebagai penyalur arus komunikasi dalam komunikasi massa mempunyai peran penting dalam membentuk perspektif individu, penonton, atau users. Bentuk komunikasi massa pada masa sekarang yang paling banyak berpengaruh dalam menciptakan opini dan perspektif adalah media digital atau media sosial. Perkembangan teknologi yang melahirkan perubahan dalam bentuk komunikasi secara digital, adalah bagian paling penting yang merubah cara pandang dan cara komunikasi manusia. Dimana sekarang ini, terutama di masa pandemic covid-19, bentuk komunikasi yang paling banyak digunakan bukan lagi komunikasi secara langsung, tetapi komunikasi melalui dunia digital

\section{Online (E-Marketing)}

Kegiatan pemasaran pada saat ini sangat pengedepankan online marketing atau elektronic marketing atau internet marketing sebagai sarana promosi, di mana banyak sekali konsumen yang menguhungkan aktivitas kesehariannya ke dalam aktivitas online untuk berbelanja, mengumpulkan informasi, hingga berkomunikasi. E-marketing menurut Kienan (2001) dalam Mardiani \& Imanuel adalah melakukan bisnis online yang bentuknya paling jelas adalah menjual produk kepada konsumen secara online. Sedangkan menurut Chaffey et al (2003) emarketing dapat di definisikan sebagai penggunaan internet dan teknologi digital yang terkait dengan pemasaran untuk mendapatkan tujuan dari pemasaran dan mendukung konsep pemasaran. Media sosial adalah media online (daring), dimana users dapat dengan mudah berpartisipasi dalam sarana pergaulan sosial secara online di internet, yang meliputi blog, sosial network atau jejaring sosial, wiki, forum dan dunia virtual (Putri et al., 2016). Secara garis 
besar media sosial berperan dalam membangun sebuah kekuatan dalam bentuk pola perilaku yang terjadi dalam berbagai kehidupan manusia. Puntoadi (Danis, 2011) mengatakan bahwa pada akhirnya media sosial memiliki fungsi dalam membangun personal branding, hubungan relasi dan ruang interaksi antara perusahaan atau organisasi dengan konsumen, serta berfungsi sebagai lembah informasi perusahaan atau organisasi.

\section{KESIMPULAN DAN SARAN}

Berdasarkan pembahasan bab diatas mengenai Kotalama Semarang, dapat disimpulkan bahwa strategi pemasaran melalui digital marketing yang dilakukan adalah dengan menerapkan digital marketing online melalui media sosial berupa Facebook, Instagram, Instant Messager yang digunakan dalam bentuk Aplikasi Chating WhatsApp dan juga menggunakan Website dan Email sebagai media pemasarannya. Selain itu juga menggunakan bauran pemasaran digital sebagai pemandu komunikasi pemasaran. Dengan itu, agar dapat selalu mengembangkan digital marketing nya untuk meningkatkan penjualan, promosi dan strategi pemasarannya pada pariwisata Kotalama

\section{Implikasi Manajerial}

Berdasarkan yang dapat disampaikan agar dapat lebih berkembang dengan digital marketing yang digunakan adalah sebagai berikut:

1. Media Sosial Untuk meningkatkan brand awareness dan meningkatkan penjualan dapat menambah beberapa akun media sosial lainnya seperti Youtube dan Twitter. Dalam Youtube dapat mengunggah kegiatan-kegiatan yang telah dilakukan seperti contohnya tour\&travel dalam bentuk video, dapat juga mengkreasikan hasil video tersebut menjadi Vlog dan digabungkan dengan testimoni dari konsumen sebagai konten dalam Youtube, yang mana ini akan lebih menguatkan rasa kepercayaan konsumen kepada dan untuk mengikuti perkembangan zaman. Sedangkan untuk dalam Twitter, dapat menuliskan sebuah Tweet tentang rekomendasi tempat wisata di Yogyakarta, Solo, dan Semarang atau dapat melakukan promosi yang menarik karena ini akan memicu konsumen untuk me-retweet unggahan dan dapat dikenal oleh masyarakat.

2. Facebook Lebih meningkatkan keaktifan di Facebook dalam mengunggah testimoni, produk yang ditawarkan lainnya, dan unggahan lainnya.

3. Website Dalam melakukan pemasaran seharusnya lebih berani untuk membuat konten semenarik mungkin dan lebih berani untuk menaikan biaya promosi dengan pembayar programer yang handal agar tampilan website terlihat lebih meyakinkan konsumen

4. Orang (People) Untuk menjadikan keberhasilan perusahaan dalam melakukan promosi suatu produk jasa melalui digital marketing, salah satunya adalah dorongan dari anggota internal perusahaan atau karyawan itu sendiri. Salah satu hal yang dapat dilakukan untuk membantu promosi sebuah perusahaan melalui digital marketing adalah membantu admin media sosial menyebarkan konten-konten yang telah di unggah di media sosial ke akun media sosial karyawan, karena ini akan membantu penyebaran promosi dan brand awareness, juga dapat menambah karyawan khusus pada bidang digital marketing online agar promosi yang ditawarkan lebih efektif dan lebih aktif dalam menjalankan media sosial. 


\section{DAFTAR PUSTAKA}

Aryanto, G. E., \& Victor, R. 2019. Penggunaan Digital Marketing Pada Jasa Usaha Fotografi "X". Jurnal STRATEGI-Jurnal Maranatha, Vol 1, nomor 2, 411-425

Brad, Kleindl and James, L, Burrow, 2005, E-Commerce Marketing, Lakewood, Ohio: Top Floor.

Chaffey, Dave., Richard, Mayer., Levin Ohnston. 2003. Internet Marketing, (2th edition). New Jersey: Prentice Hall.

Chaffey, D., Hemphill, T., \& Edmundson-Bird. 2019. Digital Business and E-Commerce Management. Seven Edition. United Kingdom: Pearson UK.

Chen-Ling\& Lie Ting. 2006. Assessment"of Internet Marketing and Competitive Strategies for Leisure Farming Industry in Taiwan. Journal of American Academy of Business: ISSN

Dharmmesta, Basu Swastha. 2014. Di petik pada 30 Maret, 2020. Manajemen pemasaran. p 138. El-Gohary,Hatem. 2010. E-Marketing- A literature Review from a Small Businesses Perspective. United States of America: International Journal of Business and Social Science. Vol. 1, No. 1, pp 214-

Dwi, A. (2012). Instagram Handbook Tips Fotografi Ponsel. Jakarta: Media Kita.

Firdaus, Muhammad. 2009. Manajemen Agribisnis. Jakarta: PT. Bumi Aksara.

Fajar Nurrakhim. 2016. Pengaruh Kualitas Produk dan Nilai Pelanggan Terhadap Kepuasan Pelanggan T-shirt (Survey Pelanggan TC Shop Online Bandung). Bandung: Universitas Pasundan Bandung.

Fisip, H. (2020, June). PROSIDING SLAMET RIYADI CONFERENCE ON PUBLIC ADMINISTRATION (SRIPA). In PROSIDING: SLAMET RIYADI CONFERENCE ON PUBLIC ADMINISTRATION (SRIPA) (Vol. 2, No. 1).

Harefa, H. P. 2015. Analisis Strategi SWOT Terhadap Peningkatan Daya Saing Pada Swalayan Bersama. Medan: Universitas Sumatera Utara.

Heinze, A., Fletcher, G., Rashid, T., \& Cruz, A. 2016. Digital and social media marketing: a results-driven approach.

Hermawan, Agus. 2012. Komunikasi Pemasaran. Jakarta: Erlangga.

Kotler, P., \& Keller, K. L. (2016). Marketing Management, 15thn Edition New Jersey:

Pearson Prentice Hall. Inc.

Mardiana, M. (n.d.). Media Sosial Dan Komunikasi Dakwah Pada Kalangan Remaja Di Sulawesi Tenggara. Jurnal Neo Societal, 5(3), 303-319.

Nasrullah, \& Rulli. (2017). Media Sosial: Perspektif Komunikasi, Budaya, dan Sosioteknologi. Remaja Rosdakarya.

Penulis, T., Enas, U., Zunaidi, A., Pribadi, Y., Syairozi, I., Andri, B., Uliansyah, A., Sunyoto, E., Sijabat, R., Sarasi, V., Sugiri, D., Hastanti, A., Rahayu, D. C., Pangestuti, A. A., \& Pratama, S. (2021). KEUANGAN NEGARA. www.penerbitwidina.com

Strauss, J., Frost, R., y Ansary, A.I. 2009. Emarketing. Pearson Prentice Hall.

Sugiyono. (2016). Metode Penelitian Kuantitatif, Kualitatif, dan R\&D. PT.Alfabeta.

Susanti, I., Syairozi, M. I., \& Lukman, H. Y. W. (2021). Analisis Sistem Manajemen Dalam Pengelolaan Bumdes Di Desa Bluluk. Jurnal Sains Sosio Humaniora, 5(2), 701-710.

Syairozi, M. I. (2017, September). ANALISIS PAJAK DAN VARIABEL MAKROEKONOMI TERHADAP PENERIMAAN PAJAK PERNGHASILAN. In Seminar Nasional Sistem Informasi (SENASIF) (Vol. 1, No. 1, pp. 338-350).

Tarigan, J., \& Sanjaya, R. 2013. Creative digital marketing. Jakarta: Elex Media Komputindo 